\section{Toxicology and Applied Pharmacology}

Toxicology and Applied Pharmacology 212 (2006) 167-178

\author{
Review
}

\title{
Diabetes and mitochondrial function: Role of hyperglycemia and oxidative stress
}

\author{
Anabela P. Rolo, Carlos M. Palmeira* \\ Center for Neurosciences and Cell Biology of Coimbra, Department of Zoology, University of Coimbra, 3004-517 Coimbra, Portugal
}

Received 19 October 2005; revised 29 December 2005; accepted 6 January 2006

Available online 20 February 2006

\begin{abstract}
Hyperglycemia resulting from uncontrolled glucose regulation is widely recognized as the causal link between diabetes and diabetic complications. Four major molecular mechanisms have been implicated in hyperglycemia-induced tissue damage: activation of protein kinase $\mathrm{C}$ (PKC) isoforms via de novo synthesis of the lipid second messenger diacylglycerol (DAG), increased hexosamine pathway flux, increased advanced glycation end product (AGE) formation, and increased polyol pathway flux. Hyperglycemia-induced overproduction of superoxide is the causal link between high glucose and the pathways responsible for hyperglycemic damage. In fact, diabetes is typically accompanied by increased production of free radicals and/or impaired antioxidant defense capabilities, indicating a central contribution for reactive oxygen species (ROS) in the onset, progression, and pathological consequences of diabetes. Besides oxidative stress, a growing body of evidence has demonstrated a link between various disturbances in mitochondrial functioning and type 2 diabetes. Mutations in mitochondrial DNA (mtDNA) and decreases in mtDNA copy number have been linked to the pathogenesis of type 2 diabetes. The study of the relationship of mtDNA to type 2 diabetes has revealed the influence of the mitochondria on nuclear-encoded glucose transporters, glucose-stimulated insulin secretion, and nuclearencoded uncoupling proteins (UCPs) in $\beta$-cell glucose toxicity. This review focuses on a range of mitochondrial factors important in the pathogenesis of diabetes. We review the published literature regarding the direct effects of hyperglycemia on mitochondrial function and suggest the possibility of regulation of mitochondrial function at a transcriptional level in response to hyperglycemia. The main goal of this review is to include a fresh consideration of pathways involved in hyperglycemia-induced diabetic complications.
\end{abstract}

(C) 2006 Elsevier Inc. All rights reserved.

Keywords: Hyperglycemia; Mitochondria; Oxidative stress; PGC-1 $\alpha$; ROS; UCP

\section{Contents}

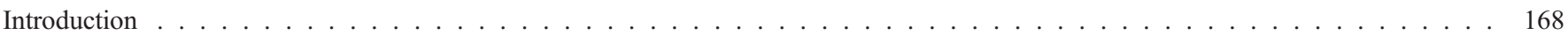

Pathological pathways for glucose toxicity - mitochondrial factors in the pathogenesis of diabetes . . . . . . . . . 168

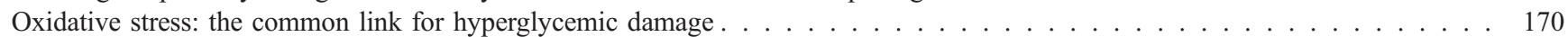

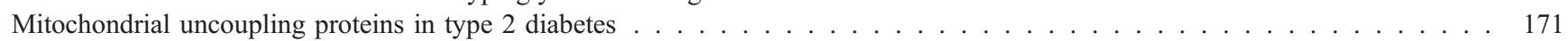

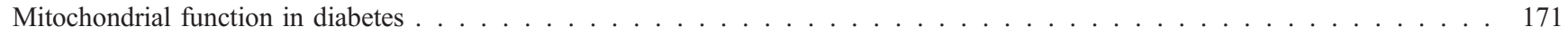

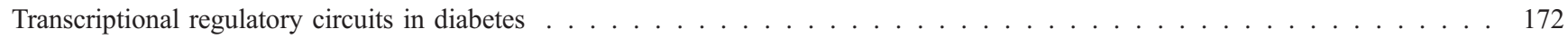

$\beta$-cell insulin secretion and mitochondrial function. . . . . . . . . . . . . . . . . . . . . . 173

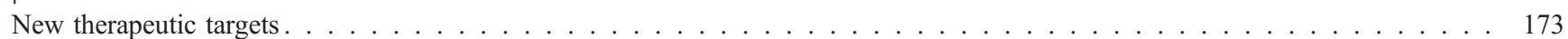

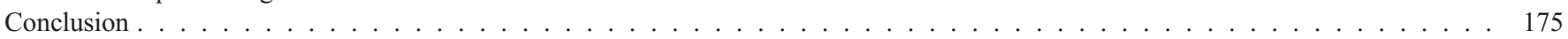

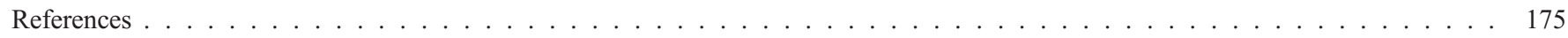

* Corresponding author. Fax: +35123982 6798 .

E-mail address: palmeira@ci.uc.pt (C.M. Palmeira). 


\section{Introduction}

The number of adults with clinical diagnosis of diabetes has been increasing dramatically worldwide. It has been estimated that the number of adults affected by diabetes in the world will grow from 135 million in 1995 to 300 million in the year 2025 . Prevalence of diabetes is higher in developed than in developing countries, but the major increase in people with diabetes will occur in developing countries. India, China, and the U.S. are currently the countries with the largest number of people with diabetes. The majority of people with diabetes in developing and developed countries are in the age range of 45-64 and 65 years, respectively. There are more women than men with diabetes, especially in developed countries (King et al., 1998).

Diabetes mellitus has been classified in two forms. Type 1 diabetes, which accounts for about $10 \%$ of all cases of diabetes, is caused by autoimmune destruction of pancreatic $\beta$-cells, producing insulin deficiency. Type 2 diabetes, the more prevalent form of diabetes, is considered a heterogeneous disease due to the multiplicity of factors that cause the observed phenotype. It results from the combination of insulin resistance and/or a $\beta$-cell secretory defect. An explosive increase in the prevalence of type 2 diabetes is predicted for the future. Some 16 million to 17 million people have the condition, and an equal number are thought to be "prediabetic", having early symptoms but not yet the full manifestation of the disease. Even children are no longer exempt to develop type 2 diabetes that until recently rarely affected people before middle age (Marx, 2002). In the U.S., about $30 \%$ of all new cases of diabetes are children with diabetes type 2 .

Diabetes mellitus is a metabolic disorder characterized by hyperglycemia and insufficiency of secretion or receptor insensitivity to endogenous insulin. While exogenous insulin and other medications can control many aspects of diabetes, assorted complications affecting the vascular system, kidney, and peripheral nerves are common and extremely costly in terms of longevity and quality of life. Not surprisingly, diabetes has a marked influence on cardiac metabolism due to altered substrate supply, impaired insulin action, and metabolic (mal) adaptations in the diabetic heart. Liver is a key organ in the maintenance of systemic glucose homeostasis in mammals. The liver regulates blood glucose levels within a very narrow range under various nutritional conditions, directing excess glucose immediately following a meal to various storage forms and providing glucose to the systemic circulation to fuel the function of many organs and tissues in the fasting state and under conditions of food deprivation.

Pathological pathways for glucose toxicity-mitochondrial factors in the pathogenesis of diabetes

Hyperglycemia resulting from uncontrolled glucose regulation is widely recognized as the causal link between diabetes and diabetic complications (Giardino et al., 1996; Brownlee, 2001). Brief episodes of hyperglycemia cause tissue damage by mechanisms involving repeated acute changes in cellular metabolism. However, exposure to high glucose also causes cumulative changes in long-lived macromolecules, which persist despite restoration of euglycemia.

A large amount of data emphasize four key metabolic pathways as being major contributors to hyperglycemiainduced cell damage (Fig. 1) (Nishikawa et al., 2000a; Brownlee, 2001; Robertson, 2004): (1) increased polyol pathway flux; (2) increased advanced glycation end product (AGE) formation; (3) activation of protein kinase $\mathrm{C}$ (PKC) isoforms; and (4) increased hexosamine pathway flux. Hyperglycemia results in increased enzymatic conversion of glucose to the polyalcohol sorbitol, with concomitant decreases in NADPH and glutathione (Brownlee, 2001). The resulting loss of antioxidant reducing equivalents results in enhanced sensitivity to oxidative stress associated with intracellular ROS. Hyperglycemia-induced overproduction of superoxide significantly inhibits glucose-6-phosphate dehydrogenase (Nishikawa et al., 2000a), the rate-limiting enzyme of the

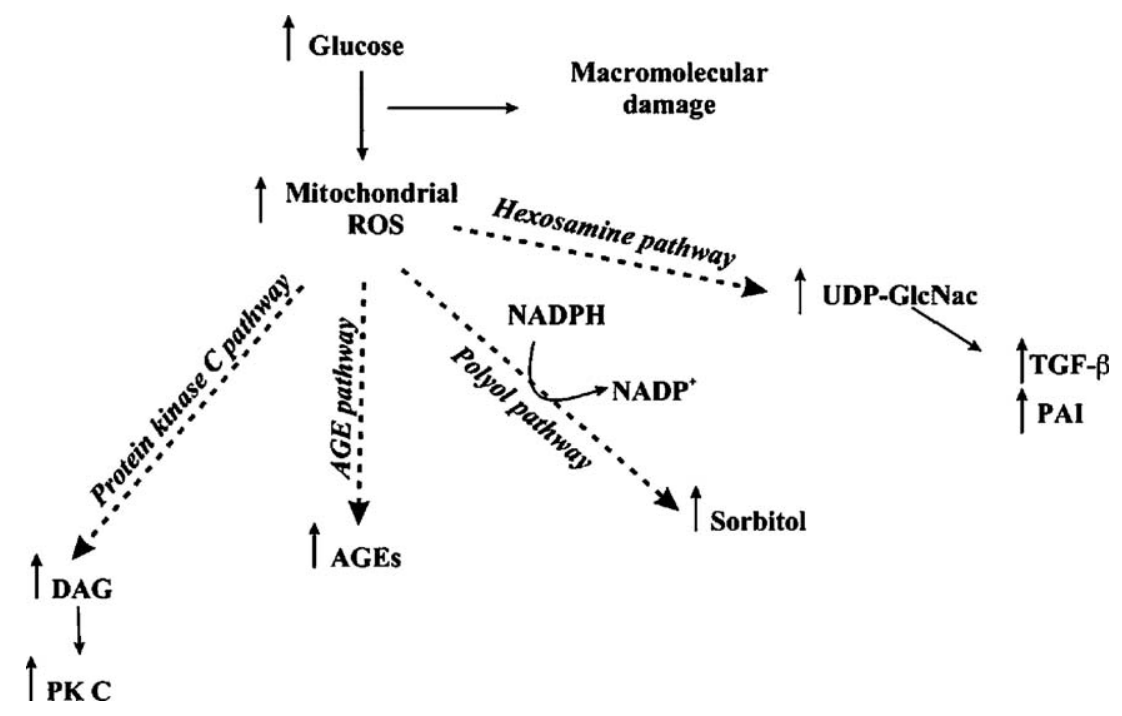

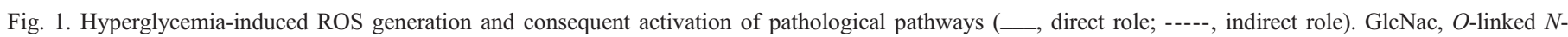
acetylglucosamine; PAI, plasminogen activator inhibitor; TGF- $\beta$, transforming growth factor- $\beta$. 
pentose phosphate pathway that is required for providing reducing equivalents to the antioxidant defense system. The product, NADPH, is the cell's principal reductant (Zhang et al., 2000; $\mathrm{Wu}$ et al., 2001) and is required for providing reducing equivalents to the glutathione peroxidase-glutathione reductase system (Fig. 2). Additionally, sorbitol is metabolized to fructose by sorbitol dehydrogenase (Fig. 2), increasing the ratio NADH/ $\mathrm{NAD}^{+}$(Brownlee, 2001). This results in oxidized triose phosphates with de novo synthesis of diacylglycerol (DAG). Increased DAG content activates protein kinase C (Fig. 2), responsible for several pathologies of diabetic complications (Brownlee, 2001).

AGEs have been implicated in the pathogenesis of the major microvascular complications of diabetes mellitus: nephropathy, neuropathy, and retinopathy (Basta et al., 2004; Cooper, 2004; Stitt et al., 2004). Glucose, although one of the least reactive reducing sugars, can react with a free amino group to form an adduct commonly referred as a Schiff base. In a Schiff base, the aldehydic carbon-oxygen double bond of the sugar is converted to a carbon-nitrogen double bond with the amine. Formation of the Schiff base is relatively fast and highly reversible. Subsequent rearrangement of the Schiff base originates an Amadori product. This reaction, which is believed to occur via an intermediate, open chain enol form, is much faster than the reverse reaction (Ulrich and Cerami, 2001). Consequently, the Amadori glycation product tends to accumulate on proteins, initiating the processes of advanced glycation. AGEs arise from autooxidation of glucose to glyoxal, decomposition of the Amadori product to 3deoxyglucosone, and fragmentation of glyceraldehyde-3phosphate and dihydroxyacetone phosphate to methylglyoxal (Brownlee, 1994). Glyoxal, methylglyoxal, and 3-deoxyglucosone are reactive intracellular dicarbonyl that react with amino groups of intracellular and extracellular proteins to form AGEs. Production of intracellular AGE precursors interferes with target cell integrity by modifying protein function or by inducing receptor-mediated production of reactive oxygen species, which have been shown to cause changes in gene expression (Yan et al., 1994).

The hexosamine biosynthesis pathway is an additional pathway of glucose metabolism that may mediate some of the toxic effects of glucose (Du et al., 2000; Brownlee, 2001). Under usual metabolic conditions, $2-5 \%$ of glucose entering cells is directed into the hexosamine pathway, beginning with the conversion of fructose 6-phosphate to glucosamine 6-phosphate by the rate-limiting enzyme glutamine:fructose-6-phosphate amidotransferase (Fig. 2) (James et al., 2002). Because hyperglycemia-induced overproduction of superoxide significantly inhibits glyceraldehyde-3-phosphate dehydrogenase activity (Du et al., 2000), this inhibition would activate all the pathways of hyperglycemic damage by diverting upstream glycolytic metabolites into these signaling pathways. During hyperglycemia, because of the increased nutrient availability, much of the excess glucose is shunted into the hexosamine pathway. The end product of this pathway, UDP- $N$-acetylglucosamine, is the substrate for the glycosylation of important intracellular factors (McClain and Crook, 1996) including transcription factors, thereby affecting the expression of many genes including plasminogen activator inhibitor-1 (PAI-1) and leads to the development of the microvascular complications of diabetes (Gabriely et al., 2002; Goldberg et al., 2002).

Until recently, there was no unifying hypothesis linking these four mechanisms. It has been shown that hyperglycemiainduced overproduction of superoxide by mitochondria (Fig. 1 ) is the trigger that drives each of these pathways (Du et al., 2000; Nishikawa et al., 2000b; Brownlee, 2001).

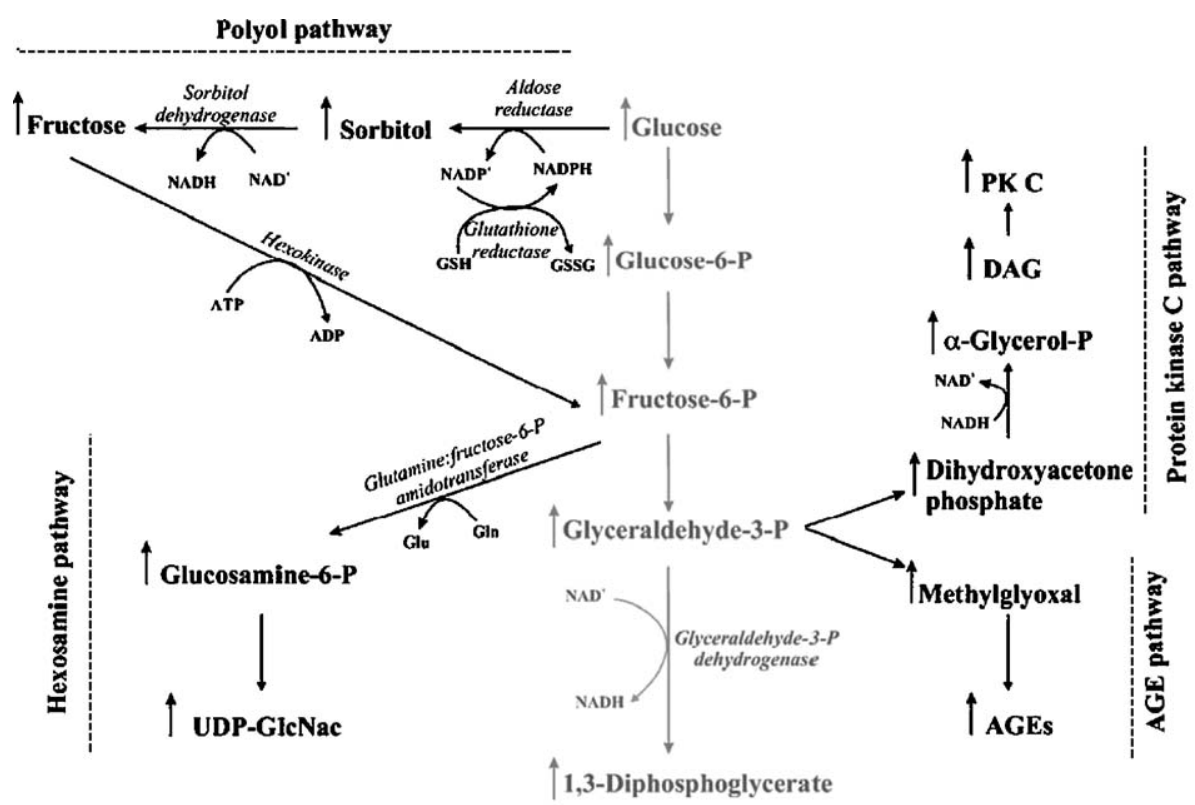

Fig. 2. Mechanisms of hyperglycemia-induced damage. AEGs, advanced glycation end products, DAG, diacylglycerol; PKC, protein kinase C. 


\section{Oxidative stress: the common link for hyperglycemic damage}

Mitochondria are the principal source of ROS in cells as the result from imperfectly coupled electron transport. Oxidative stress is widely accepted as playing a key mediatory role in the development and progression of diabetes and its complications due to increased production of free radicals and impaired antioxidant defenses (Ha and Lee, 2000; Bonnefont-Rousselot, 2002; Evans et al., 2003; Ceriello, 2003; Maritim et al., 2003).

Pyruvate derived from glycolysis is transported into the mitochondria, where it is oxidized by the tricarboxylic acid (TCA) cycle to generate NADH. Electrons deriving from oxidation of substrates are funneled through the redox carriers of the respiratory chain (complexes I, III, and IV) to the final electron acceptor, molecular oxygen. Through four-electron reduction, oxygen is converted to water. However, during normal metabolism, reactive incompletely reduced forms of oxygen, such as superoxide (Fig. 3), are produced. Normally, only $0.1 \%$ of total oxygen consumption leaks from the respiratory chain to generate ROS.

The primary factor governing mitochondrial ROS generation is the redox state of the respiratory chain (Skulachev, 1996; Lambert and Brand, 2004a). Electron transfer through the mitochondrial respiratory chain generates a proton (voltage) gradient. Under normal conditions, much of the energy of this voltage gradient is used to generate ATP as the collapse of the proton gradient through ATP synthase drives the ATP synthetic machinery. The amplitude of the electrochemical proton gradient, which is known as respiratory control, regulates the overall rate of electron transport in the respiratory chain. When the electrochemical potential difference generated by the proton gradient is high (such as in high glucose states), the life of superoxide-generating electron transport intermediates, such as ubisemiquinone, is prolonged. This occurs because the activity of the respiratory chain complexes as proton pumps is inherently governed by the transmembrane proton gradient $(\Delta \mathrm{pH})$ and the membrane potential $\left(\Delta \Psi_{\mathrm{mt}}\right)$. When sufficiently high, $\Delta \mathrm{pH}$ and $\Delta \Psi_{\mathrm{mt}}$ inhibit the proton pumps (Starkov and Fiskum, 2003). It is evident that each of the ROS-generating sites has a different redox potential, and thus each will respond differently to changes in $\Delta \mathrm{pH}$ and $\Delta \Psi_{\mathrm{mt}}$, resulting in a complex regulation of ROS generation by these membrane gradients (Lambert and Brand, 2004b). There appears to be a threshold value above which even a small increase in $\Delta \Psi_{\mathrm{mt}}$ gives rise to a large stimulation of superoxide production by mitochondria (Korshunov et al., 1997; Bodrova et al., 1998). Overall, most bioenergetic effectors, via their effects on $\Delta \mathrm{pH}$ and $\Delta \Psi_{\mathrm{m}}$, can modulate mitochondrial ROS generation. In isolated mitochondria, dissipation of membrane potential by chemical uncouplers, free fatty acids, or the presence of ADP decreases the rate of ROS generation.

How is ROS production via the mitochondrial respiratory chain a causal link between high glucose and the main pathways responsible for hyperglycemic damage? The prevailing hypothesis is that hyperglycemia-induced increase in electron transfer donors ( $\mathrm{NADH}$ and $\mathrm{FADH}_{2}$ ) increases electron flux through the mitochondrial electron transport chain. Consequently, there is an increase of the ATP/ADP ratio and hyperpolarization of the mitochondrial membrane potential. This high electrochemical potential difference generated by the proton gradient leads to partial inhibition of the electron transport in complex III, resulting in an accumulation of electrons to coenzyme Q. In turn, this drives partial reduction of $\mathrm{O}_{2}$ to generate the free radical anion superoxide (Nishikawa et al., 2000b; Brownlee, 2001). It is this accelerated reduction of coenzyme $Q$ and generation of ROS that is believed to be the fundamental source for mitochondrial dysfunction that plays a critical role in diabetes-related metabolic disorders and tissue histopathology.

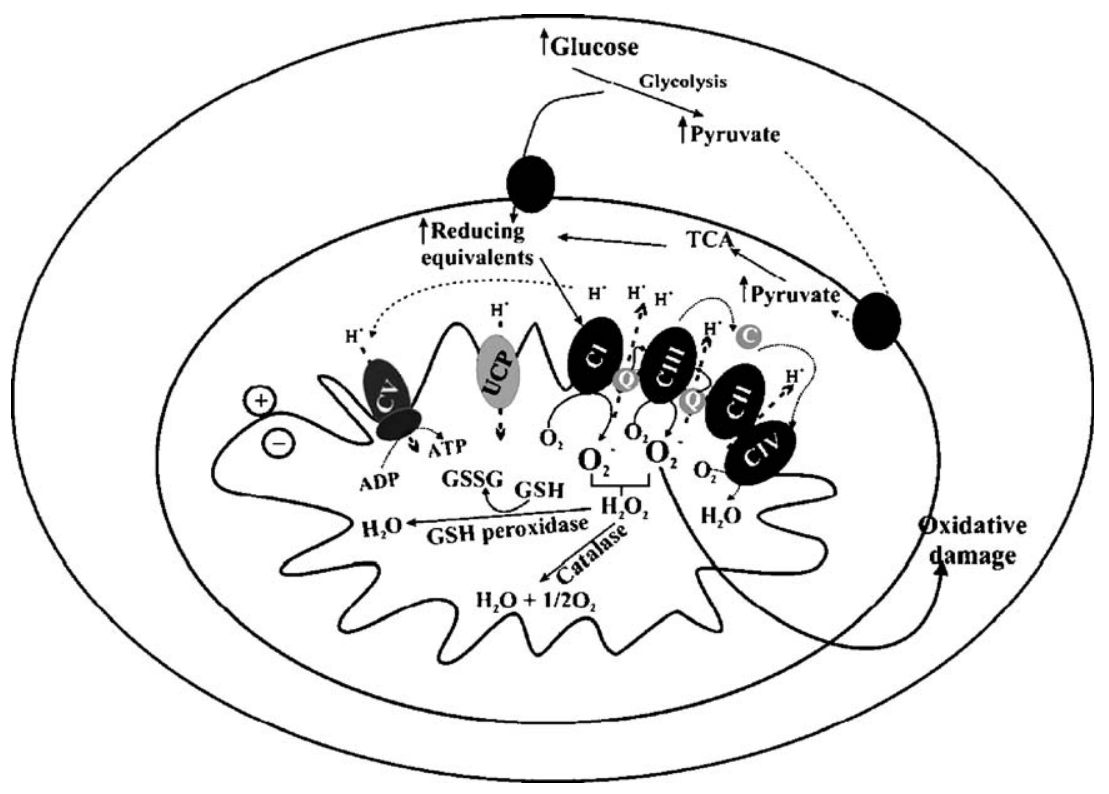

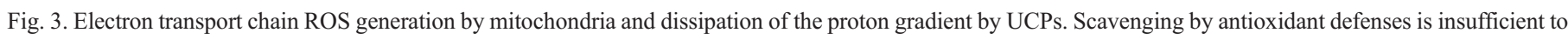

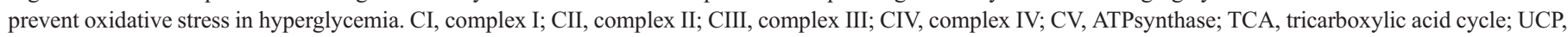
uncoupling protein. 
Nishikawa and colleagues showed that, in bovine aortic endothelial cells exposed to high glucose, addition of CCCP (an uncoupler of oxidative phosphorylation that abolishes $\Delta \Psi_{\mathrm{mt}}$ ) decreases ROS production (Nishikawa et al., 2000b). Russell and colleagues also demonstrated that high glucose-generated ROS is coupled with hyperpolarization of $\Delta \Psi_{\mathrm{mt}}$ in neurons (Russell et al., 2002).

\section{Mitochondrial uncoupling proteins in type 2 diabetes}

UCPs are members of a family of nuclear-encoded mitochondrial carriers, which act as proton carrier proteins in the mitochondrial inner membrane. This facilitates the proton leak across the membrane (Fig. 3), able to modulate the coupling between the respiratory electron transport chain and ATP synthesis. UCP-induced proton leakiness causes partial depolarization of the mitochondrial transmembrane potential (Dullo and Samec, 2001).

The UCP subtypes, UCP-1, UCP-2, and UCP-3, differ with respect to tissue distribution and probably also function. Increased induction UCP-1 leads to thermogenesis. The functions of UCP-2 and UCP-3 are still unclear but are believed to cause a mild uncoupling of respiration that governs mitochondrial membrane potential and the accumulation of oxygen radicals and/or control of the $\mathrm{NAD}^{+} / \mathrm{NADH}$ ratio. A number of laboratories have demonstrated that UCP2 expression is inversely correlated with the level of ROS generation by respiring mitochondria (Nègre-Salvayre et al., 1997; Skulachev, 1998). In the context of diabetes, overexpression of UCPs in cultured neurons blocks glucoseinduced programmed cell death by preventing mitochondrial hyperpolarization and formation of ROS (Vincent et al., 2004). This suggests a central role for UCPs in the regulation of mitochondrial membrane hyperpolarization and ROS formation in glucose-mediated neuronal injury. $\beta$ cells subjected to oxidative stress were found to combat $\mathrm{H}_{2} \mathrm{O}_{2}$ toxicity through the induction of UCP-2 ( $\mathrm{Li}$ et al., 2001). Additionally, muscle cells overexpressing UCP-3 were shown a significant decrease in mitochondrial ROS production, although there were no differences in glucose oxidation and mitochondrial membrane potential (MacLellan et al., 2005).

Besides reduction of mitochondrial ROS generation, UCPs play a key role in determining the relationship in regulating fatty acid and glucose oxidation (Boss et al., 2000). The observation that UCP-3 was upregulated in type 2 diabetic rat hearts supports a regulatory role for UCPs in fatty acid oxidation. UCP-3 is proposed to export fatty acid out of mitochondria to permit continued high rates of fatty acid oxidation under conditions of fatty acid over-supply. UCP-3 may also act as a "flipase" to protect mitochondria from potentially damaging fatty acids (Carley and Severson, 2005). As impaired fatty acid metabolism and ROS handling are important precursors in muscular insulin resistance, UCPs appear as possible therapeutic targets in type 2 diabetes (Langin, 2003). Indeed, decreased UCP-3 content is associated with insulin resistance in muscle of prediabetic and diabetic individuals, although with no clear explanation for UCP-3 function (Schrauwen et al., 2001). Mice overexpressing UCP-1 display enhanced skeletal muscle glucose transport, despite decreased ATP content and mitochondrial proteins (Han et al., 2004). In high-fat-diet-induced diabetes, hepatic UCP-1 expression markedly improved insulin resistance (Ishigaki et al., 2005). However, the perspective of UCPs as a therapeutic approach has to be carefully addressed. In fact, excessive proton leak will induce mitochondrial uncoupling and subsequent impairment of cell bioenergetics. Furthermore, these observations cannot be generalized for all tissues. It has been described that upregulation of UCP-2 in pancreatic $\beta$-cells is associated with decreased ATP production, closure of ATP-sensitive $\mathrm{K}^{+}$channels, and impairment of glucose-stimulated insulin secretion (Brownlee, 2003; Lowell and Shulman, 2005). Lack of UCP-2 dramatically improves insulin secretion and decreases hyperglycemia in leptindeficient mice (Langin, 2003).

\section{Mitochondrial function in diabetes}

Impairment of mitochondrial function is intrinsically related with diabetes. The observation that reduced rates of ATP synthesis in subjects with a family history of diabetes occur before the onset of impaired glucose tolerance (Petersen et al., 2004) indicates the significance of mitochondrial dysfunction in diabetes progression. GotoKakizaki (GK) rat and streptozotocin (STZ)-treated rat are models for diabetes type 2 and diabetes type 1, respectively. These models have been used to study several aspects of mitochondrial bioenergetics and function in diabetic states. Parameters such as oxygen consumption, transmembrane potential, calcium loading capacity, resistance or susceptibility to oxidative stress, and the mitochondrial permeability transition (MPT) have been addressed.

Metabolic alterations in liver mitochondria were evaluated in both models, at initial and advanced states of disease. The observed mitochondrial alterations as a function of age are different in both models (GK rats and STZ-treated rats), indicating differential adaptation mechanisms to counteract high glucose levels typical of the disease (Ferreira et al., 1999b, 2003). Mitochondria isolated from liver of 9 weeks type 1 diabetic rat showed decreased respiratory chain activity, characterized by decreased membrane potential and respiratory ratios. In contrast, liver mitochondria from 6 months GK rats presented increased respiratory ratios. Additionally, the increase in the repolarization rate and ATPase activity observed in GK rats is presumably related to an improved efficiency of $\mathrm{F}_{0} \mathrm{~F}_{1}$ ATPase. Titrations with oligomycin, an inhibitor of the ATP synthase, indicated that diabetic GK liver mitochondria require excess oligomycin pulses to completely abolish phosphorylation, relative to control mitochondria. This suggests that liver mitochondria of diabetic GK rats are provided with extra catalytic units relative to control mitochondria of normal rats (Palmeira et al., 1999). Such early adaptive responses of mitochondrial function to diabetic stress may reflect changes in gene expression induced by hyperglycemia as a mechanism for cell adaptation to glucose toxicity. 
Liver mitochondria from GK rats were less susceptible to lipid peroxidation, which was correlated with an increase in mitochondrial vitamin E ( $\alpha$-tocopherol) content and GSH/ GSSG ratio. Moreover, glutathione reductase activity was significantly increased, whereas the glutathione peroxidase was decreased in diabetic animals. Superoxide dismutase activity was unchanged (Ferreira et al., 1999a). In GK rats, mitochondria isolated from brain were more susceptible to in vitro oxidative damage than brain mitochondria from normal rats. This decreased susceptibility was inversely related to their $\alpha$-tocopherol and coenzyme Q (CoQ) content (Santos et al., 2001). Thus, the difference in the antioxidant defense mechanisms in brain and liver mitochondria of GK rats may correspond to different adaptive responses of the cells to the increased oxidative stress in diabetes. Testis mitochondrial preparations from GK exhibited lower susceptibility to lipid peroxidation, with increased mitochondrial glutathione and coenzyme Q9 contents, whereas vitamin E was not changed (Palmeira et al., 2001). This indicates a role for mitochondria in the association between diabetes mellitus and impairment of testicular function, ultimately leading to reduced fertility.

Both types of diabetes affected negatively cardiac mitochondrial bioenergetics (Santos et al., 2003; Oliveira et al., 2004). Reduced mitochondrial calcium uptake was observed in heart mitochondria from STZ-treated rats. This was related with enhanced susceptibility to MPT induction rather than damage to the calcium uptake machinery (Oliveira et al., 2003). Interestingly, heart mitochondria from GK rats were less susceptible to the induction of MPT, showing larger calcium accumulation before the overall loss of mitochondrial impermeability (Oliveira et al., 2001). Different antioxidant approaches (vitamin E or coenzyme Q10) administration in GK rats showed no success in reversing the diabetic phenotype (Oliveira et al., 2004).

\section{Transcriptional regulatory circuits in diabetes}

Each mitochondrion contains 2-10 copies of circular, supercoiled, double-stranded DNA found unprotected within the inner mitochondrial membrane. The close proximity of mtDNA to ROS-generating sites makes mtDNA more vulnerable to oxidative damage. The increase in oxidative stress during hyperglycemia may thus lead to mutations in mtDNA (Maassen et al., 2004). In fact, it has been estimated that $0.1-$ $9.0 \%$ of the diabetic population is due to a mutation in mtDNA (Lamson and Plaza, 2002). Maternally inherited type 2 diabetes was one of the first mitochondrially inherited diabetic conditions to be identified (Ballinger et al., 1992). mtDNA depletion has also been suggested as causative factor in diabetes pathogenesis. Mitochondria of $\beta$-cells from GK rats were shown to have decreased volume and mtDNA content, although an increased number of mitochondria per unit area in the islet tissue (Serradas et al., 1995). Alterations in mitochondrial biogenesis in insulin-resistant relatives of type 2 diabetes have also been observed. Prediabetic patients were found to have significant mtDNA depletion before the onset of disease (Lee et al., 1998). mtDNA content has also been shown to affect the expression of nuclear-encoded glucose transporters (Park et al., 2001).

The majority of mitochondrial proteins are synthesized in the nucleus and shuttled to the mitochondria. Only 13 proteins involved with oxidative phosphorylation are exclusively encoded by mtDNA. Since mitochondrial number and function require both nuclear and mitochondrial-encoded genes, coordinated mechanisms exist to regulate the two genomes and determine the overall oxidative capacity (Kelly and Scarpulla, 2004). Peroxisome proliferator-activated receptor- $\gamma$ (PPAR $\gamma$ ) coactivator- $1 \alpha(\mathrm{PGC}-1 \alpha)$ is an integrator of the molecular regulatory circuit involved in the transcriptional control of cellular energy metabolism, including mitochondrial biogenesis, hepatic gluconeogenesis, and fatty acid $\beta$-oxidation (Puigserver and Spiegelman, 2003). PGC-1 $\alpha$ serves as a direct transcriptional coactivator of nuclear and non-nuclear receptor transcription factors involved in cellular energy metabolism, such as PPAR $\gamma$ and nuclear respiratory factors (NRFs) (Kelly and Scarpulla, 2004). The interplay between NRFs and PGC-1 plays an important role in the physiological control of respiratory chain proteins expression (Wu et al., 1999). NRFs also regulate mitochondrial transcription factor A (Tfam), a nuclearly encoded factor that translocates to mitochondria and activates its replication and transcription (Virbasius and Scarpulla, 1994).

Reduced expression of oxidative phosphorylation genes has been observed in type 2 diabetes (Mootha et al., 2003), accompanied by decreased expression of PGC- $1 \alpha$ in prediabetic and diabetic muscle (Patti et al., 2003). Additionally, changes observed in the expression of nuclear-encoded mitochondrial proteins correlate functional and morphological changes in the mitochondria in various states of insulin resistance. Insulin resistance is associated with decreased protein content of the ATP synthase $\beta$ subunit (Hojlund et al., 2003). High-fat diet, which leads to insulin resistance due to increased concentrations of free fatty acids, downregulates PGC- $1 \alpha$ mRNA and genes encoding proteins for complexes I, II, III, and IV (Sparks et al., 2005). PGC- $1 \alpha$, both mRNA and protein, is also significantly reduced in adipose tissue of insulin-resistant subjects (Hammarstedt et al., 2003). Taken together, the results suggest that decreased PGC-1 $\alpha$ expression may be responsible for decreased expression of NRF-dependent genes. This may contribute to the metabolic disturbances characteristic of insulin resistance and diabetes mellitus.

Diabetic heart failure may be causally associated with alterations in cardiac energy metabolism. Fuel selection and capacity for ATP production in the normal and failing heart are dictated by several metabolic regulatory events at the level of gene expression. Decline in the capacity for ATP production caused by progressive impairment of mitochondrial function is a gradual step in the progression to heart failure of any cause. Fetal heart depends on glucose and the adult heart on glucose and fatty acids. The switch between fatty acid oxidation and glucose on the adult heart leads to a healthy metabolic situation (Huss and Kelly, 2005). In the insulin-resistant and diabetic heart, fatty acid oxidation is increased and glucose utilization is 
diminished. Long-term consequence of fatty acid oxidation is mitochondrial dysfunction. A number of mechanisms may be responsible for enhanced fatty acid utilization in type 2 diabetic hearts such as increased fatty acid uptake into the cell and mitochondria, increased UCP-3 expression, and stimulation of peroxisome proliferator-activated receptor- $\alpha(\operatorname{PPAR} \alpha)$. Dysregulation of PPAR $\alpha$ and its control of cardiac fatty acid utilization have been detected in several cardiomyopathic disease states (Carley and Severson, 2005). This chronic activation of PPAR $\alpha$ in the heart has several metabolic and functional consequences. PPAR $\alpha$, along with its coactivator PGC-1, has a role in the regulation of fatty acid oxidation, mitochondrial biogenesis, and ATP production (Ram, 2003). Mice that express constitutively PPAR $\alpha$ show increased fatty acid uptake and oxidation similarly to the diabetic heart. A reduction in glucose utilization with cardiac insulin resistance is also characteristic (Park et al., 2005). Cardiac-specific induction of PGC- $1 \alpha$ leads to increased mitochondrial biogenesis, with ultrastructural derangements (Russell et al., 2004), coincident with signs of mitochondrial oxidative stress reported in hearts of mice with life-long type 1 diabetes. These data indicate that chronic activation of PGC- $1 \alpha$ and/or PPAR $\alpha$ in diabetic heart plays a role in the development of mitochondrial and myocardial dysfunction.

\section{$\beta$-cell insulin secretion and mitochondrial function}

In pancreatic $\beta$-cells, the ATP/ADP ratio determines the opening probability of the $\mathrm{K}_{\mathrm{ATP}}$ channel involved in insulin secretion. Changes in this ratio as a result of mitochondrial dysfunction will affect the setting of the glucose-induced insulin secretion response (Lowell and Shulman, 2005).

Glucose is transported across the cellular membrane by glucose transporters (GLUT) mainly by GLUT-1. Glycolysis transforms glucose to pyruvate, of which more than $90 \%$ is shuttled into the mitochondria. The ratio of ATP/ADP increases as processing of the glucose through glycolysis, TCA cycle, and oxidative phosphorylation increases. This increase in ATP/ADP ratio causes the ATP-sensitive $\mathrm{K}^{+}$channels to close, causing depolarization of voltage-sensitive $\mathrm{Ca}^{2+}$ channel, triggering the exocytosis of insulin secretory vesicles (Maechler and Wollheim, 2001).

The critical importance of oxidative phosphorylation in glucose-stimulated insulin secretion has been demonstrated by several in vitro studies. Specific inhibitors of the complexes of the mitochondrial respiratory chain were all found to inhibit insulin release from pancreatic islet cells (MacDonald and Fahien, 1990). Cells lacking mtDNA (rho0 cells) also loose their ability to progressive enhancement of insulin secretion by glucose stimulation. These cells depleted of mtDNA have disproportionate changes in the nuclear-tomitochondrial composition of electron transport complexes and a loss of respiratory efficiency, relying on glycolysis for ATP production. Repopulation of rho0 cells with foreign mtDNA restores the property of glucose-stimulated insulin secretion (Soejima et al., 1996). This suggests that mtDNA and the mitochondrial respiratory function are necessary for glucose-stimulated insulin secretion. $\beta$-cell pathology of human mitochondrial diabetes has been reproduced in Tfam-mutant mice. These animals, which have knockout of the nuclear gene Tfam in pancreatic $\beta$-cell, develop diabetes, with impaired insulin secretion and beta-cell loss. Tfammutant mice also display severe mtDNA depletion, deficient oxidative phosphorylation, and abnormal-appearing mitochondria. Tfam is a transcriptional activator imported to mitochondria, where it is essential for mtDNA expression and maintenance. This animal model provides genetic evidence for a critical role of the respiratory chain in insulin secretion and $\beta$-cell function (Silva et al., 2000).

Chronic exposure of the $\beta$-cell to supraphysiologic concentrations of glucose causes defective insulin gene expression accompanied by marked decreases in insulin content and abnormal insulin secretion (Robertson et al., 1992, 2003). Hyperglycemia-induced superoxide production by mitochondria is an important aspect in $\beta$-cell glucose toxicity (Brownlee, 2003; Lowell and Shulman, 2005). The link is the subsequent activation of UCP-2 by superoxide (Krauss et al., 2003), with ROS leading to irreversible decreases in the level of the transcription factor PDX-1, critical for insulin gene expression (Robertson et al., 2003). Furthermore, activation of UCP-2 by superoxide also decreases the ATP/ADP ratio and thus reduces the insulin secretory response (Lowell and Shulman, 2005). Agingrelated processes probably contribute to the gradual deterioration of $\beta$-cell function (Maassen et al., 2004). Indeed, insulin resistance is a major factor in the pathogenesis of type 2 diabetes in the elderly, associated with decreased mitochondrial oxidative phosphorylation activity. This indicates an association between age-related decline in mitochondrial function and insulin resistance (Petersen et al., 2003). The mitochondrial theory of aging postulates that increased ROS production, mtDNA damage accumulation, and progressive respiratory chain dysfunction are mechanisms by which mitochondria contribute to the aging process. A recent study of genetically manipulated mice provided evidence that such alterations may play a causal role in aging (Dufour and Larsson, 2004).

\section{New therapeutic targets}

Treatment strategies that focus on decreasing oxidative stress (Ceriello, 2003; Green et al., 2004) as well as enhancing mitochondrial function might present important options for diabetes treatment (Table 1). Coenzyme Q10 has shown some clinical significance in a number of clinical trials. However, it has failed to show consistent clinical benefit (Lamson and Plaza, 2002). Coenzyme Q10 administration to GK rats showed no success in preventing mitochondrial dysfunction (Oliveira et al., 2004). The ineffectiveness of currently existing antioxidants in ameliorating oxidative-stress-mediated diseases points to the considerable interest in developing mitochondria-targeted antioxidants. Triphenylphosphonium-based and amino-acidand peptide-based antioxidants have been shown to protect mitochondria against oxidative insult, indicating that 
Table 1

Therapeutic strategies in diabetes

\begin{tabular}{|c|c|c|c|}
\hline Target & Strategy & Observations & References \\
\hline ROS & $\begin{array}{l}\text { Target antioxidants to } \\
\text { mitochondria to modulate } \\
\text { ROS production }\end{array}$ & $\begin{array}{l}\text { CCCP decreases ROS production in bovine } \\
\text { aortic endothelial cells exposed to high glucose } \\
\text { Decreased susceptibility of liver mitochondria } \\
\text { isolated from GK rats to oxidative damage } \\
\text { correlated with increased mitochondrial } \\
\text { vitamin E content } \\
\text { Triphenylphosphonium-based and amino-acid- } \\
\text { and peptide-based antioxidants have been } \\
\text { shown to protect mitochondria against } \\
\text { oxidative insult. }\end{array}$ & $\begin{array}{l}\text { Palmeira et al., 2001; Santos et al., 2001; } \\
\text { Bonnefont-Rousselot, 2002; Lamson and Plaza, 2002; } \\
\text { Nishikawa et al., 2002a, 2002b; Ceriello, 2003; } \\
\text { Maritim et al., 2003; Sheu et al., } 2005\end{array}$ \\
\hline AGEs & $\begin{array}{l}\text { Prevention or slow AGEs } \\
\text { formation and reversal AGE } \\
\text { cross-links between proteins }\end{array}$ & $\begin{array}{l}\text { Partial prevention by AGE inhibitors of } \\
\text { diabetic complications in animal models } \\
\text { Inhibition of glycation reactions and AGEs } \\
\text { formation by pyridoxamine }\end{array}$ & $\begin{array}{l}\text { Hammes et al., 1991; Soulis-Liparota et al., 1991; } \\
\text { Nakamura et al., 1997; Voziyan and Hudson, } 2005\end{array}$ \\
\hline PARP & $\begin{array}{l}\text { Prevention of } \mathrm{NAD}^{+} \text {depletion } \\
\text { and glyceraldehyde-3- } \\
\text { phosphate dehydrogenase } \\
\text { inhibition }\end{array}$ & $\begin{array}{l}\text { Inhibition of PARP protects against diabetic } \\
\text { cardiovascular dysfunction in preclinical models } \\
\text { Hyperglycemia-induced activation of PKC } \\
\text { isoforms, hexosaminase pathway flux, } \\
\text { and AGE formation is prevented by blocking } \\
\text { PARP activity }\end{array}$ & $\begin{array}{l}\text { Pacher and Szabo, 2005; Szabo, 2005; } \\
\text { Woon and Threadgill, } 2005\end{array}$ \\
\hline PPAR $\gamma$ and UCPs & $\begin{array}{l}\text { Modulation of PPAR } \gamma \text { and } \\
\text { UCPs expression by TZD }\end{array}$ & $\begin{array}{l}\text { Pioglitazone upregulates UCP-2 gene expression } \\
\text { in skeletal muscle of hyperglycemic KK mice } \\
\text { NC-2100 activates PPAR } \gamma \text { in vivo and induces } \\
\text { expression of UCP- } 2 \text { in isolated pancreatic islets } \\
\text { PPAR } \gamma \text { overexpression induces } \\
\text { UCP-2 protein expression }\end{array}$ & $\begin{array}{l}\text { Shimabukuro et al., 1997; Fukui et al., 2000; } \\
\text { Ito et al., } 2004\end{array}$ \\
\hline FXR & $\begin{array}{l}\text { Modulation of lipid metabolism } \\
\text { and hepatic gluconeogenesis }\end{array}$ & $\begin{array}{l}\text { FXR expression is reduced in diabetic rat models. } \\
\text { Administration of insulin to STZ-induced diabetic } \\
\text { rats restores FXR mRNA to normal levels } \\
\text { SHP positively regulates glucose-stimulated } \\
\text { insulin secretion in } \beta \text {-cells and restores } \\
\text { glucose sensitivity in UCP2-overexpressing } \beta \text {-cells }\end{array}$ & Duran-Sandoval et al., 2005; Suh et al., 2004 \\
\hline
\end{tabular}

mitochondrially targeted antioxidants are future promises for disease treatment (Sheu et al., 2005).

Research into AGEs has been conducted with the goal to unravel prospective pharmacological agents for preventing or treating diabetic complications. The goals are to prevent or slow AGEs formation and break the AGE cross-links between proteins and possibly reverse the damage. The potential importance of AGEs in the pathogenesis of diabetic complications has been shown by the partial prevention of two structurally unrelated AGE inhibitors in various functional and structural manifestations of diabetic disease in animal models (Hammes et al., 1991; Soulis-Liparota et al., 1991; Nakamura et al., 1997). Pyridoxamine has also been shown to inhibit glycation reactions and the formation of AGEs (Voziyan and Hudson, 2005). Pharmacological agents have been placed in clinical trials to combat AGE processes in man. Pimagedine, which inhibits AGEs formation in experimental models, did not demonstrate a statistically significant beneficial effect on the progression of nephropathy resulting from type 1 diabetes (Bolton et al., 2004).

Experimental evidence implicates poly(ADP-ribose) polymerase (PARP) as a causative factor in the pathogenesis of diabetes and diabetic complications, such as acute endothelial dysfunction (Szabo, 2005). PARP catalyzes the transfer of ADP-ribose units from the substrate $\mathrm{NAD}^{+}$to acceptor proteins, biosynthesizing polyanionic poly(ADP-ribose) polymers. Hyperglycemia-induced ROS overproduction leads to DNA strand breakage and subsequent PARP activation. This initiates an energy-consuming, inefficient cellular metabolic cycle, which leads to $\mathrm{NAD}^{+}$depletion and slows the rate of glycolysis, electron transport, and ATP formation. Additionally, it inhibits glyceraldehyde-3-phosphate dehydrogenase by poly(ADP-ribosy)lation (Pacher and Szabo, 2005). PARP also promotes the activation of various pro-inflammatory signal transduction pathways. The therapeutic potential of PARP inhibition in the prevention or reversal of diabetic complications has been the subject of intensive research work, but only recently PARP inhibitors entered clinical trial (Woon and Threadgill, 2005).

Recent developments concerning a novel thiazolidinedione class of insulin-sensitizing agents represent a significant advance in antidiabetic therapy. This class of drugs activates peroxisome proliferator-activated receptors, which play a central role in regulating the storage and catabolism of dietary fats (Ram, 2003; Kota et al., 2005). PPAR $\gamma$ is the major molecular target for the insulin-sensitizing thiazolidinedione (TZD) drugs. PPAR $y$ has been shown to modulate the transcription activities of a great number of genes involved in energy storage and utilization, including the mitochondrial uncoupling proteins, UCP-1, UCP-2, and UCP-3 (Kelly et al., 
1998). Several studies illustrate that thiazolidinediones (TZDs) stimulate UCP-2 expression in different cell lines (Camirand et al., 1998; Hammarstedt and Smith, 2003). More specifically, pioglitazone has been shown to upregulate UCP-2 gene expression in skeletal muscle of hyperglycemic KK mice (Shimokawa et al., 1998), as well as troglitazone in pancreatic islets of Zucker diabetic fatty rats (Shimabukuro et al., 1997). Fukui and colleagues showed that NC-2100, a novel thiazolidinedione, activates PPAR $\gamma$ in vivo and induces expression of UCP-2 in white adipose tissue (Fukui et al., 2000). More recently, Ito and colleagues showed that in isolated pancreatic islets PPAR $y$ overexpression induced UCP-2 protein expression (Ito et al., 2004). In this respect, PPAR $\gamma$ appears to be of promising pharmacological interest since it was identified as the target of TZDs used in the treatment of non-insulin-dependent diabetes mellitus (Olefsky, 2000; Ram, 2003).

Another potential therapeutic target is the farnesoid $\mathrm{X}$ receptor (FXR), a nuclear hormone receptor that functions as the bile acid receptor. In addition to the critical role that FXR plays in bile acid metabolism and transport, it regulates a variety of genes important in lipid metabolism (De Fabiani et al., 2004; Claudel et al., 2005). The first indication of a potential role for FXR in diabetes and the metabolic syndrome comes from the observation that hepatic FXR expression is reduced in diabetic rat models and that administration of insulin to STZ-induced diabetic rats restored FXR mRNA to normal levels. It has been demonstrated that FXR expression is regulated by glucose via the pentose phosphate pathway and suggested that alterations of FXR expression in diabetics may contribute to dysregulation of lipid and bile acid metabolism (Duran-Sandoval et al., 2005).

Hepatic gluconeogenesis is significantly increased in type 2 diabetics, contributing to the observed fasting hyperglycemia. Pharmacological inhibition of this pathway has been proposed as a method to restore insulin sensitivity, which has been validated by the antidiabetic drug metformin, that reduces hepatic glucose production via inhibition of gluconeogenesis (Barthel and Schmoll, 2003). One pivotal point of regulation of the gluconeogenesis pathway is the expression of phosphoenolpyruvate carboxykinase (PEPCK), suggesting a potential point of pharmacological intervention. FXR plays a role in carbohydrate metabolism via regulation of PEPCK gene expression (Stayrook et al., 2005). FXR participates in the regulation of the fasting-induced gluconeogenic response via induction of the small heterodimer partner (SHP). SHP is an orphan nuclear receptor whose function in pancreatic $\beta$-cells is unclear. SHP positively regulates glucose-stimulated insulin secretion in $\beta$-cells and restores glucose sensitivity in UCP2overexpressing $\beta$-cells by enhancing mitochondrial glucose metabolism (Suh et al., 2004).

\section{Conclusion}

Hyperglycemia elicits an increase in ROS production, presumably from the mitochondrial respiratory chain. ROS plays a central role in mediating various metabolic defects associated with the diabetic state. Therefore, inhibition of ROS production and/or enhancement of ROS scavenging will prove to be beneficial therapies. Damage to mtDNA has been shown in certain situations to result in the type 2 diabetes phenotype. Another aspect of dysfunction is associated with the quantitative reduction in mtDNA copy number. Alterations in metabolic regulators and glucose-stimulated insulin secretion are also associated with mitochondrial dysfunction in diabetes.

\section{References}

Ballinger, S.W., Shoffner, J.M., Hedaya, E.V., Trounce, I., Polak, M.A., Koontz, D.A., Wallace, D.C., 1992. Maternally transmitted diabetes and deafness associated with a $10.4 \mathrm{~kb}$ mitochondrial DNA deletion. Nat. Genet. 1, $11-15$.

Barthel, A., Schmoll, D., 2003. Novel concepts in insulin regulation of hepatic gluconeogenesis. Am. J. Physiol. 285, E685-E692.

Basta, G., Schmidt, A.M., De Caterina, R., 2004. Advanced glycation end products and vascular inflammation: implications for accelerated atherosclerosis in diabetes. Cardiovasc. Res. 63, 582-592.

Bodrova, M.E., Dedukhova, V.I., Mokhova, E.N., Skulachev, V.P., 1998. Membrane potential generation coupled to oxidation of external NADH in liver mitochondria. FEBS Lett. 435, 269-274.

Bolton, W.K., Cattran, D.C., Williams, M.E., Adler, S.G., Appel, G.B., Cartwright, K., Foiles, P.G., Freedman, B.I., Raskin, P., Ratner, R.E., Spinowitz, B.S., Whittier, F.C., Wuerth, J.P., 2004. Randomized trial of an inhibitor of formation of advanced glycation end products in diabetic nephropathy. Am. J. Nephrol. 24, 32-40.

Boss, O., Hagen, T., Lowell, B.B., 2000. Uncoupling proteins 2 and 3: potential regulators of mitochondrial energy metabolism. Diabetes 49, 143-156.

Bonnefont-Rousselot, D., 2002. Glucose and reactive oxygen species. Curr. Opin. Clin. Nutr. Metab. Care 5, 561-568.

Brownlee, M., 1994. Glycation and diabetic complications. Diabetes 43, 836-841.

Brownlee, M., 2001. Biochemistry and molecular cell biology of diabetic complications. Nature 414, 813-820.

Brownlee, M., 2003. A radical explanation for glucose-induced $\beta$-cell dysfunction. J. Clin. Invest. 112, 1788-1790.

Camirand, A., Marie, V., Rabelo, R., Silva, J.E., 1998. Thiazolidinediones stimulate uncoupling protein-2 expression in cell lines representing white and brown adipose tissues and skeletal muscle. Endocrinology 139, 428-431.

Carley, A.N., Severson, D.L., 2005. Fatty acid metabolism is enhanced in type 2 diabetic hearts. Biochim. Biophys. Acta 1734, 112-126.

Ceriello, A., 2003. New insights on oxidative stress and diabetic complications may lead to a "causal" antioxidant therapy. Diabetes Care 26, 1589-1596.

Cooper, M.E., 2004. Importance of advanced glycation end products in diabetes-associated cardiovascular and renal disease. Am. J. Hypertens. $17,31 \mathrm{~S}-38 \mathrm{~S}$

Claudel, T., Staels, B., Kuipers, F., 2005. The farnesoid X receptor. A molecular link between bile acid and lipid and glucose homeostasis. Arterioscler., Thromb., Vasc. Biol. 25, 2020-2030.

De Fabiani, E., Mitro, N., Godio, C., Gilardi, F., Caruso, D., 2004. Bile acid signaling to the nucleus: finding new connections in the transcriptional regulation of metabolic pathways. Biochimie 86, 771-778.

Du, X.-L., Edelstein, D., Rossetti, L., Fantus, I.G., Goldberg, H., Ziyadeh, F., Wu, J., Brownlee, M., 2000. Hyperglycemia-induced mitochondrial superoxide overproduction activates the hexosamine pathway and induces plasminogen activator inhibitor-1 expression by increasing Sp 1 glycosylation. Proc. Natl. Acad. Sci. U.S.A. 97, 12222-12226.

Dufour, E., Larsson, N.G., 2004. Understanding aging: revealing order out of chaos. Biochim. Biophys. Acta 1658, 122-132.

Dullo, A.G., Samec, S., 2001. Uncoupling proteins: their roles in adaptive thermogenesis and substrate metabolism reconsidered. Br. J. Nutr. 86, $123-139$.

Duran-Sandoval, D., Cariou, B., Fruchart, J.-C., Staels, B., 2005. Potential regulatory role of the farnesoid $\mathrm{X}$ receptor in the metabolic syndrome. Biochimie 87, 93-98. 
Evans, J.L., Goldfine, I.D., Maddux, B.A., Grodsky, G.M., 2003. Are oxidative stress-activated signaling pathways mediators en insulin resistance and $\beta$ cell dysfunction? Diabetes 52, 1-8.

Ferreira, F.M.L., Palmeira, C.M., Matos, M.J., Seiça, R., Santos, M.S., 1999a. Decreased susceptibility to lipid peroxidation of Goto-Kakizaki rats: relationship to mitochondrial antioxidant capacity. Life Sci. 65, 1013-1025.

Ferreira, F.M.L., Seiça, R., Santos, M.S., Palmeira, C.M., 1999b. Age-related alterations in liver mitochondrial bioenergetics of diabetic Goto-Kakizaki rats. Acta Diabetol. 36, 173-177.

Ferreira, F.M., Moreno, A.J., Seiça, R., Santos, M.S., Palmeira, C.M., 2003. Diabetes and mitochondrial bioenergetics: alterations with age. J. Biochem. Mol. Toxicol. 17, 214-222.

Fukui, Y., Masui, S., Osada, S., Umesono, K., Motojima, K., 2000. A new thiazolidinedione, $\mathrm{NC}-2100$, which is a weak PPAR $\gamma$-activator, exhibits potent antidiabetic effects and induces uncoupling protein 1 in white adipose tissue of KKAy obese mice. Diabetes 4, 759-767.

Gabriely, I., Yang, X.M., Cases, J.A., Ma, X.H., Rossetti, L., Barzilai, N., 2002. Hyperglycemia induces PAI-1 gene expression in adipose tissue by activation of the hexosamine biosynthetic pathway. Atherosclerosis 160 , $115-122$.

Giardino, I., Edelstein, D., Brownlee, M., 1996. BCL-2 expression or antioxidants prevent hyperglycemia induced formation of intracellular advanced glycation endproducts in bovine endothelial cells. J. Clin. Invest. 97, 1422-1428.

Goldberg, H.J., Whiteside, C.I., Fantus, I.G., 2002. The hexosamine pathway regulates the plasminogen activator inhibitor-1 gene promoter and Sp1 transcriptional activation through protein kinase $\mathrm{C}^{\prime} \beta \mathrm{I}$ and $-^{\prime} \delta$. J. Biol. Chem. 277, 33833-33841.

Green, K., Brand, M.D., Murphy, M.P., 2004. Prevention of mitochondrial oxidative damage as a therapeutic strategy in diabetes. Diabetes 53, S110-S118.

Ha, H., Lee, H.B., 2000. Reactive oxygen species as glucose signaling molecules in mesangial cells cultured under high glucose. Kidney Int. 58, S19-S25.

Hammarstedt, A., Smith, U., 2003. Thiazolidinediones (PPAR gamma ligands) increase IRS-1, UCP-2 and C/EBPalpha expression, but not transdifferentiation, in L6 muscle cells. Diabetologia 46, 48-52.

Hammarstedt, A., Jansson, P.A., Wesslau, C., Yang, X., Smith, U., 2003. Reduced expression of PGC-1 and insulin-signaling molecules in adipose tissue is associated with insulin resistance. Biochem. Biophys. Res. Commun. 301, 578-582.

Hammes, H.P., Martin, S., Federlin, K., Geisen, K., Brownlee, M., 1991. Aminoguanidine treatment inhibits the development of experimental diabetic retinopathy. Proc. Natl. Acad. Sci. U.S.A. 88, 11555-11559.

Han, D.H., Nolte, L.A., Ju, J.S., Coleman, T., Holloszy, J.O., Semenkovich, C.F., 2004. UCP-mediated energy depletion in skeletal muscle increases glucose transport despite lipid accumulation and mitochondrial dysfunction. Am. J. Physiol.: Endocrinol. Metab. 286, E347-E353.

Hojlund, K., Wrzesinski, K., Larsen, P.M., Fey, S.J., Roepstorff, P., Handberg, A., Dela, F., Vinten, J., McCormack, J.G., Reynet, C., Beck-Nielsen, H., 2003. Proteome analysis reveals phosphorylation of ATP synthase betasubunit in human skeletal muscle and proteins with potential roles in type 2 diabetes. J. Biol. Chem. 278, 10436-10442.

Huss, J.M., Kelly, D.P., 2005. Mitochondrial energy metabolism in heart failure: a question of balance. J. Clin. Invest. 115, 547-555.

Ishigaki, Y., Katagiri, H., Yamada, T., Ogihara, T., Imai, J., Uno, K., Hasegawa, Y., Gao, J., Ishihara, H., Shimosegawa, T., Sakoda, H., Asano, T., Oka, Y., 2005. Dissipating excess energy stored in the liver is a potential treatment strategy for diabetes associated with obesity. Diabetes 54, 322-332.

Ito, E., Ozawa, S., Takahashi, K., Tanaka, T., Katsuta, H., Yamaguchi, S., Maruyama, M., Takizawa, M., Katahira, H., Yoshimoto, K., Nagamatsu, S., Ishida, H., 2004. PPAR $\gamma$ overexpression selectively suppresses insulin secretory capacity in isolated pancreatic islets through induction of UCP-2 protein. Biochem. Biophys. Res. Commun. 324, 810-814.

James, L.R., Tang, D., Ingram, A., Ly, H., Thai, K., Cai, L., Scholey, J.W., 2002. Flux through the hexosamine pathway is a determinant of nuclear factor $\kappa \mathrm{B}$ dependent promoter activation. Diabetes 51, 1146-1156.

Krauss, S., Zhang, C.Y., Scorrano, L., Dalgaard, L.T., St-Pierre, J., Grey, S.T.,
Lowell, B.B., 2003. Superoxide-mediated activation of uncoupling protein 2 causes pancreatic beta cell dysfunction. J. Clin. Invest. 112, 1831-1842.

Kelly, D.P., Scarpulla, R.C., 2004. Transcriptional regulatory circuits controlling mitochondrial biogenesis and function. Genes Dev. 18, 357-368.

Kelly, L.J., Vicario, P.P., Thompson, G.M., Candelore, M.R., Doebber, T.W., Ventre, J., Wu, M.S., Meurer, R., Forrest, M.J., Conner, M.W., Cascieri, M. A, Moller, D.E., 1998. Peroxisome proliferator-activated receptors $\gamma$ and $\gamma$ mediate in vivo regulation of uncoupling protein (UCP-1, UCP-2, UCP-3) gene expression. Endocrinology 139, 4920-4927.

Kota, B.P., Huang, T.H.-W., Roufogalis, B.D., 2005. An overview on biological mechanisms of PPARs. Pharmacol. Res. 51, 85-94.

King, H., Aubert, R.E., Herman, W.H., 1998. Global burden of diabetes, 19952025: prevalence, numerical estimates, and projections. Diabetes Care 21, 1414-1431.

Korshunov, S.S., Skulachev, V.P., Starkov, A.A., 1997. High protonic potential actuates a mechanism of production of reactive oxygen species in mitochondria. FEBS Lett. 416, 15-18.

Lambert, A.J., Brand, M.D., 2004a. Inhibitors of the quinone binding site allow rapid superoxide production from mitochondrial NADH: ubiquinone oxidoreductase (complex I). J. Biol. Chem. 279, 39414-39420.

Lambert, A.J., Brand, M.D., 2004b. Superoxide production by NADH: ubiquinone oxidoreductase (complex I) depends on the $\mathrm{pH}$ gradient across the mitochondrial inner membrane. Biochem. J. 382, 511-517.

Lamson, D.W., Plaza, S.M., 2002. Mitochondrial factors in the pathogenesis of diabetes: a hypothesis for treatment. Altern. Med. Rev. 7, 94-111.

Langin, D., 2003. The role of uncoupling protein 2 in the development of type 2 diabetes. Drugs Today (Barc.) 39, 287-295.

Lee, H.K., Song, J.H., Shin, C.S., Park, D.J., Park, K.S., Lee, K.U., Koh, C.S., 1998. Decreased mitochondrial DNA content in peripheral blood precedes the development of non-insulin-dependent diabetes mellitus. Diabetes Res. Clin. Pract. 42, 161-167.

Li, L.X., Skorpen, F., Egeberg, K., Jorgensen, I.H., Grill, V., 2001. Uncoupling protein-2 participates in cellular defense against oxidative stress in clonal beta-cells. Biochem. Biophys. Res. Commun. 282, 273-277.

Lowell, B.B., Shulman, G.I., 2005. Mitochondrial dysfunction and type 2 diabetes. Science 307, 384-387.

Maassen, J.A., 'T Hart, L.M., Van Essen, E., Heine, R.J., Nijpels, G., Jahangir Tafrechi, R.S., Raap, A.K., Janssen, G.M., Lemkes, H.H., 2004. Mitochondrial diabetes: molecular mechanisms and clinical presentation. Diabetes 53, S103-S109.

McClain, D.A., Crook, E.D., 1996. Hexosamines and insulin resistance. Diabetes 45, 1003-1009.

MacDonald, M.J., Fahien, L.A., 1990. Insulin release in pancreatic islets by a glycolytic and a Krebs cycle intermediate: contrasting patterns of glyceraldehyde phosphate and succinate. Arch. Biochem. Biophys. 279, 104-108.

MacLellan, J.D., Gettits, M.F., Gowing, A., Smith, P.J., Wheeler, M.B., Harper, M.E., 2005. Physiological increases in uncoupling protein 3 augment fatty acid oxidation and decrease reactive oxygen species production without uncoupling respiration in muscle cells. Diabetes 54, 2343-2350.

Maechler, P., Wollheim, C.B., 2001. Mitochondrial function in normal and diabetic $\beta$-cells. Nature 414, 807-812.

Maritim, A.C., Sanders, R.A., Watkins III, J.B., 2003. Diabetes, oxidative stress, and antioxidants: a review. J. Biochem. Mol. Toxicol. 17, 24-38.

Marx, J., 2002. Unraveling the causes of diabetes. Science 296, 686-689.

Mootha, V.K., Lindgren, C.M., Eriksson, K.F., Subramanian, A., Sihag, S., Lehar, J., Puigserver, P., Carlsson, E., Ridderstrale, M., Laurila, E., Houstis, N., Daly, M.J., Patterson, N., Mesirov, J.P., Golub, T.R., Tamayo, P., Spiegelman, B., Lander, E.S., Hirschhorn, J.N., Altshuler, D., Groop, L.C., 2003. PGC-1alpha-responsive genes involved in oxidative phosphorylation are coordinately downregulated in human diabetes. Nat. Genet. 34, 267-273.

Nakamura, S., Makita, Z., Ishikawa, S., Yasumura, K., Fujii, W., Yanagisawa, K., Kawata, T., Koike, T., 1997. Progression of nephropathy in spontaneous diabetic rats is prevented by OPB-9195, a novel inhibitor of advanced glycation. Diabetes 46, 895-899.

Nègre-Salvayre, A., Hirtz, C., Carrera, G., Cazenave, R., Troly, M., Salvayre, R., Pénicaud, L., Casteilla, L., 1997. A role for uncoupling protein-2 as a 
regulator of mitochondrial hydrogen peroxide generation. FASEB J. 11, $809-815$.

Nishikawa, T., Edelstein, D., Du, X.L., Yamagishi, S.-I., Matsumura, T., Kaneda, Y., Yorek, M.A., Beebe, D., Oates, P.J., Hammes, H.-P., Giardino, I., Brownlee, M., 2000a. Normalizing mitochondrial superoxide production blocks three pathways of hyperglycaemic damage. Nature 404, $787-790$.

Nishikawa, T., Edelstein, D., Brownlee, M., 2000b. The missing link: a single unifying mechanism for diabetic complications. Kidney Int. 58, S26-S30.

Olefsky, J.M., 2000. Treatment of insulin resistance with peroxisome proliferator-activated receptor $\gamma$ agonists. J. Clin. Invest. 106, 467-472.

Oliveira, P.J., Rolo, A.P., Seiça, R., Palmeira, C.M., Santos, M.S., Moreno, A.J., 2001. Decreased susceptibility of heart mitochondria from diabetic GK rats to mitochondrial permeability transition induced by calcium/phosphate. Biosci. Rep. 21, 45-53.

Oliveira, P.J., Seiça, R., Coxito, P.M., Rolo, A.P., Palmeira, C.M., Santos, M.S., Moreno, A.J., 2003. Enhanced permeability transition explains the reduced calcium uptake in cardiac mitochondria from streptozotocin-induced diabetic rats. FEBS Lett. 554, 511-514.

Oliveira, P.J., Seiça, R., Santos, D.L., Rolo, A.P., Sardao, V.A., Ferreira, F.M.L., Palmeira, C.M., Santos, M.S., Moreno, A.J., 2004. Vitamin E or coenzyme Q10 administration are not fully advantageous for heart mitochondrial function in diabetic Goto Kakizaki rats. Mitochondrion 3, 337-345.

Pacher, P., Szabo, C., 2005. Role of poly(ADP-Ribose) Polymerase-1 activation in the pathogenesis of diabetic complications: endothelial dysfunction, as a common underlying theme. Antioxid. Redox Signal. 7, 1568-1580.

Palmeira, C.M., Ferreira, F.M.L., Santos, D.L., 1999. Higher efficiency of the liver phosphorylative system in diabetic Goto-Kakizaki (GK) rats. FEBS Lett. 458, 103-106.

Palmeira, C.M., Santos, D.L., Seiça, R., Moreno, A.J., Santos, M.S., 2001. Enhanced mitochondrial testicular antioxidant capacity in Goto-Kakizaki (GK) diabetic rats: role of coenzyme Q. Am. J. Physiol. 28, C1023-C1028.

Park, K.S., Nam, K.J., Kim, J.W., Lee, Y.B., Han, C.Y., Jeong, J.K., Lee, H.K., Pak, Y.K., 2001. Depletion of mitochondrial DNA alters glucose metabolism in SK-Hep1 cells. Am. J. Physiol.: Endocrinol. Metab. 280, E1007-E1014.

Park, S.Y., Cho, Y.R., Finck, B.N., Kim, H.J., Higashimori, T., Hong, E.G., Lee, M.K., Danton, C., Deshmukh, S., Cline, G.W., Wu, J.J., Bennett, A.M., Rothermel, B., Kalinowski, A., Russell, K.S., Kim, Y.B., Kelly, D.P., Kim, J. K., 2005. Cardiac-specific overexpression of peroxisome proliferatoractivated receptor-alpha causes insulin resistance in heart and liver. Diabetes $54,2514-2524$

Patti, M.E., Butte, A.J., Crunkhorn, S., Cusi, K., Berria, R., Kashyap, S., Miyazaki, Y., Kohane, I., Costello, M., Saccone, R., Landaker, E.J., Goldfine, A.B., Mun, E., DeFronzo, R., Finlayson, J., Kahn, C.R., Mandarino, L.J., 2003. Coordinated reduction of genes of oxidative metabolism in humans with insulin resistance and diabetes: potential role of PGC1 and NRF1. Proc. Natl. Acad. Sci. U.S.A. 100, 8466-8471.

Petersen, K.F., Befroy, D., Dufour, S., Dziura, J., Ariyan, C., Rothman, D.L., DiPietro, L., Cline, G.W., Shulman, G.I., 2003. Mitochondrial dysfunction in the elderly: possible role in insulin resistance. Science 300, 1140-1142.

Petersen, K.F., Dufour, S., Befroy, D., Garcia, R., Shulman, G.I., 2004. Impaired mitochondrial activity in the insulin-resistant offspring of patients with type 2 diabetes. N. Engl. J. Med. 350, 664-671.

Puigserver, P., Spiegelman, B.M., 2003. Peroxisome proliferator-activated receptor-gamma coactivator 1 alpha (PGC-1 alpha): transcriptional coactivator and metabolic regulator. Endocr. Rev. 24, 78-90.

Ram, V.J., 2003. Therapeutic significance of peroxisome proliferator-activated modulators in diabetes. Drugs Today 39, 609-632.

Robertson, R.P., 2004. Chronic oxidative stress as a central mechanism for glucose toxicity in pancreatic islet beta cells in diabetes. J. Biol. Chem. 279, 42351-42354.

Robertson, R.P., Zhang, H.J., Pyzdrowski, K.L., Walseth, T.F., 1992. Preservation of insulin mRNA levels and insulin secretion in HIT cells by avoidance of chronic exposure to high glucose concentrations. J. Clin. Invest. 90, 320-325

Robertson, R.P., Harmon, J., Tran, P.O., Tanaka, Y., Takahashi, H., 2003. Glucose toxicity in beta-cells: type 2 diabetes, good radicals gone bad, and the glutathione connection. Diabetes 52, 581-587.
Russell, J.W., Golovoy, D., Vincent, A.M., Mahendru, P., Olzmann, J.A., Mentzer, A., Feldman, E.L., 2002. High glucose-induced oxidative stress and mitochondrial dysfunction in neurons. FASEB J. 16, $1738-1748$

Russell, L.K., Mansfield, C.M., Lehman, J.J., Kovacs, A., Courtois, M., Saffitz, J.E., Medeiros, D.M., Valencik, M.L., McDonald, J.A., Kelly, D.P., 2004. Cardiac-specific induction of the transcriptional coactivator peroxisome proliferator-activated receptor gamma coactivator-1 alpha promotes mitochondrial biogenesis and reversible cardiomyopathy in a developmental stage-dependent manner. Circ. Res. 94, 525-533.

Santos, M.S., Santos, D.L., Palmeira, C.M., Seiça, R., Moreno, A.J., Oliveira, C.R., 2001. Brain and liver mitochondria isolated from diabetic GotoKakizaki rats shown different susceptibility to induced-oxidative stress. Diabetes/Metab. Res. Rev. 17, 223-230.

Santos, D.L., Palmeira, C.M., Seiça, R., Dias, J., Mesquita, J., Moreno, A.J., Santos, M.S., 2003. Diabetes and mitochondrial oxidative stress: a study using heart mitochondria from the diabetic Goto-Kakizaki rat. Mol. Cell. Biochem. 246, 163-170.

Schrauwen, P., Hesselink, M.K., Blaak, E.E., Borghouts, L.B., Schaart, G., Saris, W.H., Keizer, H.A., 2001. Uncoupling protein 3 content is decreased in skeletal muscle of patients with type 2 diabetes. Diabetes 50, 2870-2873.

Serradas, P., Giroix, M.H., Saulnier, C., Gangnerau, M.N., Borg, L.A., Welsh, M., Portha, B., Welsh, N., 1995. Mitochondrial deoxyribonucleic acid content is specifically decreased in adult, but not fetal, pancreatic islets of the Goto-Kakizaki rat, a genetic model of noninsulin-dependent diabetes. Endocrinology 136, 5623-5631.

Sheu, S.S., Nauduri, D., Anders, M.W., 1995. Targeting antioxidants to mitochondria: a new therapeutic direction. Biochim. Biophys. Acta $256-265$.

Shimabukuro, M., Zhou, Y.T., Lee, Y., Unger, R.H., 1997. Induction of uncoupling protein-2 mRNA by troglitazone in the pancreatic islets of Zucker diabetic fatty rats. Biochem. Biophys. Res. Commun. 237, 359-361.

Shimokawa, T., Kato, M., Watanabe, Y., Hirayama, R., Kurosaki, E., Shikama, H., Hashimoto, S., 1998. In vivo effects of pioglitazone on uncoupling protein-2 and -3 mRNA levels in skeletal muscle of hyperglycemic KK mice. Biochem. Biophys. Res. Commun. 251, 374-378.

Silva, J.P., Kohler, M., Graff, C., Oldfors, A., Magnuson, M.A., Berggren, P.O., Larsson, N.G., 2000. Impaired insulin secretion and beta-cell loss in tissuespecific knockout mice with mitochondrial diabetes. Nat. Genet. 26, 336-340.

Skulachev, V.P., 1996. Role of uncoupled and non-coupled oxidations in maintenance of safely low levels of oxygen and its one-electron reductants. Q. Rev. Biophys. 29, 169-202.

Skulachev, V.P., 1998. Uncoupling: new approaches to an old problem of bioenergetics. Biochim. Biophys. Acta 1363, 100-124.

Soejima, A., Inoue, K., Takai, D., Kaneko, M., Ishihara, H., Oka, Y., Hayashi, J.I., 1996. Mitochondrial DNA is required for regulation of glucose-stimulated insulin secretion in a mouse pancreatic beta cell line, MIN6. J. Biol. Chem. 271, 26194-26199.

Soulis-Liparota, T., Cooper, M., Papazoglou, D., Clarke, B., Jerums, G., 1991. Retardation by aminoguanidine of development of albuminuria, mesangial expansion, and tissue fluorescence in streptozocin-induced diabetic rat. Diabetes 40, 1328-1334.

Sparks, L.M., Xie, H., Koza, R.A., Mynatt, R., Hulver, M.W., Bray, G.A., Smith, S.R., 2005. A high-fat diet coordinately downregulates genes required for mitochondrial oxidative phosphorylation in skeletal muscle. Diabetes 54, 1926-1933.

Starkov, A., Fiskum, G., 2003. Regulation of brain mitochondrial $\mathrm{H} 2 \mathrm{O} 2$ production by membrane potential and $\mathrm{NAD}(\mathrm{P}) \mathrm{H}$ redox state. J. Neurochem. $68,1101-1107$

Stayrook, K.R., Bramlett, K.S., Savkur, R.S., Ficorilli, J., Cook, T., Christe, M. E., Michael, L.F., Burris, T.P., 2005. Regulation of carbohydrate metabolism by the farnesoid X receptor. Endocrinology 146, 964-991.

Stitt, A.W., Frizzell, N., Thorpe, S.R., 2004. Advanced glycation and advanced lipoxidation: possible role in initiation and progression of diabetic retinopathy. Curr. Pharm. Des. 10, 3349-3360. 
Suh, Y.-H., Kim, S.-Y., Lee, H.-Y., Jang, B.C., Bae, J.H., Sohn, J.-N., Bae, J.-H., Suh, S.-I., Park, J.-W., Lee, K.-U., Song, D.-K., 2004. Overexpression of short heterodimer partner recovers impaired glucose-stimulated insulin secretion of pancreatic $\beta$-cells overexpressing UCP2. J. Endocrinol. 183, $133-144$.

Szabo, C., 2005. Roles of poly(ADP-ribose) polymerase activation in the pathogenesis of diabetes mellitus and its complications. Pharmacol. Res. 52, $60-71$.

Ulrich, P., Cerami, A., 2001. Protein glycation, diabetes, and aging. Recent Prog. Horm. Res. 56, 1-21.

Vincent, A.M., Olzmann, J.A., Brownlee, M., Sivitz, W.I., Russell, W., 2004. Uncoupling proteins prevent glucose-induced neuronal oxidative stress and programmed cell death. Diabetes 53, 726-734.

Virbasius, J.V., Scarpulla, R.C., 1994. Activation of the human mitochondrial transcription factor A gene by nuclear respiratory factors: a potential regulatory link between nuclear and mitochondrial gene expression in organelle biogenesis. Proc. Natl. Acad. Sci. U.S.A. 91, 1309-1313.

Voziyan, P.A., Hudson, B.G., 2005. Pyridoxamine as a multifunctional pharmaceutical: targeting pathogenic glycation and oxidative damage Cell. Mol. Life Sci. 62, 1671-1681

Woon, E.C., Threadgill, M.D., 2005. Poly(ADP-ribose)polymerase inhibitionWhere now? Curr. Med. Chem. 12, 2373-2392.

Wu, Z., Puigserver, P., Andersson, U., Zhang, C., Adelmant, G., Mootha, V., Troy, A., Cinti, S., Lowell, B., Scarpulla, R.C., Spiegelman, B.M., 1999. Mechanisms controlling mitochondrial biogenesis and function through the thermogenic coactivator PGC-1. Cell 98, 115-124.

Wu, G., Haynes, T.E., Li, H., Yan, W., Meininger, C.J., 2001. Glutamine metabolism to glucosamine is necessary for glutamine inhibition of endothelial nitric oxide synthesis. Biochem. J. 353, 245-252.

Yan, S.D., Schmidt, A.M., Anderson, G.M., Zhang, J., Brett, J., Zou, Y.S., Pinsky, D., Stern, D., 1994. Enhanced cellular oxidant stress by the interaction of advanced glycation end products with their receptors/binding proteins. J. Biol. Chem. 269, 9889-9897.

Zhang, Z., Apse, K., Pang, J., Stanton, R.C., 2000. High glucose inhibits glucose-6-phosphate dehydrogenase via cAMP in aortic endothelial cells. J. Biol. Chem. 275, 40042-40047. 